\title{
Preschool Education in Belize: Research on the Current Status and Implications for the Future
}

\author{
Alberto Luis August \\ College of Education \& Human Services, University of North Florida, Jacksonville, 32224, USA
}

\begin{abstract}
Early childhood education is the foundation of a child's education. Belize is a developing country and is striving towards the development of its educational system. This study describes the status of preschool education in Belize using three methods of collecting data: survey, observations, and interviews. A national survey described the education, qualifications, and experience of preschool teachers and directors/principals. Three instruments, Early Childhood Environment Rating Scale-Revised (ECERS-R), Early Childhood Environment Rating Scale-Extension (ECERS-E), and the Caregiver Interaction Scale (CIS), were scored in 41 preschools to describe the physical environment, curriculum implementation, and teacher-child interaction, respectively. A modification of the ECERS-R and ECERS-E, named the Early Childhood Environment Rating for Belize (ECERS-B), was created. The modified version is an instrument that is compatible with the culture of Belize. The quality of preschools environments were at the minimal with evidence of positive teacher-child interaction. A one-way ANOVA indicated significant differences with teacher education level, suggesting that teachers with education qualifications higher than a high school diplo ma had higher scores on the ECERS-B. Finally, four major stakeholders were interviewed to find out their perception of early childhood education in Belize. Belize has implemented initiatives to improve the quality of early childhood education. Recommendations for policy, practice, and future research are suggested.
\end{abstract}

Keywords Preschool Education, Early Childhood, Belize

\section{Introduction}

At the time of the research, the problem concerning early childhood education in Belize was that little was known concerning the current status of early childhood education. Limited, if any, empirical studies had been conducted directly related to early childhood education in Belize. Preschools are typically rated on two dimensions of quality-process quality and structural quality. Process quality consists of the experiences that occur in the preschool settings such as child-teacher interactions, activities, learn ing opportunities, health and safety routines, and the relationship maintained with parents. Structural quality consists of the group-size of children in the setting, space availability for children to move around, the adult-child ratio, teachers' income, and the education and training of teachers and support staff[1]. Minimal, if any, information was known about the process quality and the structural quality of the preschools in Belize.

Preschools were not equally distributed around the country of Belize. Preschool programs benefit young

* Corresponding author:

aaugust fbs@yahoo.com (Alberto Luis August)

Published online at http://journal.sapub.org/edu

Copyright (C) 2012 Scientific \& Academic Publishing. All Rights Reserved children of low-income backg round[2]. In Belize, the rural areas, especially those of Stann Creek, Toledo, and Orange Walk, are the poorer areas in the country and the low numbers of preschools in these areas do not adequately serve these areas.

Many preschools were privately managed, especially those in the urban areas. This meant that young children from lower socio-economic backgrounds did not have an opportunity to attend preschools due to the high cost of attending. The registration fee and monthly tuition varied among the different institutions. For example, in 2006, one school charged a registration fee of BZE \$120.00 per term (a term is equivalent to one semester and three terms are in a 1-year program) plus a tuition of BZE $\$ 10.00$ per week. Another school in the same location charged a registration fee of BZE $\$ 80.00$ per term and a monthly tuition of BZE $\$ 40.00$. Preschool directors/owners were free to determine the fees and tuition for attending their schools.

No official Early Childhood Education Policy existed in Belize. A draft copy was in progress, but the need for an official policy was urgent if the intention was to improve the quality of preschool education in Belize.

Belize had a well-defined education structure adopted from England. The church-state system that operated and managed the primary school education system was stable and exerted much effort to educate children from 5 to 14 
years of age. The high school system was well-defined and maintained a similar church-state system to provide children with a high school diploma. At least one tertiary level institution was established in each district around the country to provide higher level education degrees to those who can afford it or had interest to pursue a higher level degree. The one education area which may be considered the most crucial but lacked a vivid definition concerning its current status was preschool education, hence the purpose of this research study.

\section{Purpose and Research Questions}

Prior to this research, little was known about the current status of preschool education in Belize. No empirical studies had been conducted that reported the demographic data of preschool teachers and the structural and process quality of preschool programs in Belize. Many preschools were private institutions that were unevenly distributed around the country and were not catered to young children it benefited the most-students of low-income backgrounds. The purpose of this research study was to describe the current status of preschool education in Belize. This descriptive study was done by addressing five specific questions that were derived from one general question.

The general question addressed was the following: What is the current status of preschool education in Belize? This question was answered by five specific questions.

1) What are the education, qualifications, and experiences of preschool teachers?

2) What is the quality of the internal and external structural environ ment of preschools?

3) What is the quality of the curriculum, the instructional strategies, and the activities used by preschool teachers?

4) What is the quality of social interaction between caregivers and young children?

5) What are the perceptions of preschool education by major stakeholders?

\section{Methodology}

A survey that was previously created[3] was modified for the cultural aspects of Belize and was used to collect demographic data (such as education, qualifications, and experiences) fro $\mathrm{m} 100$ preschool teachers and directors/prin cipals.

Forty-one (41) preschool centers from the six different districts in the country were selected via stratified random sampling to collect data using three instruments: the Early Childhood Environment Rating Scale-Revised (ECERS-R) [4], the Early Childhood Environment Rating Scale-Extension (ECERS-E)[5], and the Caregiver Interaction Scale (CIS)[6]. These instruments were used to collect data on the physical environment, curriculum strategies and activities, and teacher-child interaction, respectively.

Ten open-ended questions were developed to interview major stakeholders in admin istrative ro les in the area of early childhood education. These stakeholders included a person from the National Preschool Unit, two preschool district coordinators, and an early childhood education instructor of a higher-degree preschool program.

\section{Results}

The results from the ECERS-R, ECERS-E, the ECERS-B, and the CIS are indicated below. The ECERS yielded a statistically significant score of $\mathbf{2 . 7 1}, \alpha=.88$ with the sample of 43 preschools that was observed in Belize. A Pearson Correlations test indicated that teachers with higher education (above high school diplo ma) scored higher on the items assessed than teachers with lower education (a high school diplo ma or below). After modification of the ECERS, the ECERS-B was developed. The ECERS-B factored out all the culturally inappropriate items. This instrument is suitable to use in Belize. The results of a Pearson Correlations test indicated that teachers with higher education (above high school diploma) scored higher on the items assessed than teachers with lower education (a high school diploma or below).

\subsection{Cul tural Modifications of ECERS}

After modification of the ECERS, the ECERS-B (Early Childhood Environment Rating Scale for Belize) was developed. The ECERS-B factored out all the culturally inappropriate items. The score increased to 3.02, $\alpha=.75$. This instrument is suitable to use in Belize.

\subsection{CIS Results}

Because the nature of the CIS instrument was not designed for an overall score, separate alpha coefficients and mean scores were obtained for each subscale, positive relationship $(\alpha=.92, M=2.60, S D=0.56)$, punitiveness $(\alpha=.90, M=$ $1.98, S D=0.58)$, permissiveness $(\alpha=.76, M=2.10, S D=$ $0.53)$, and detachment $(\alpha=.69, M=1.71, S D=0.49$. Each subscale had acceptable internal consistency reliability.

For the positive relationship subscale, a high score indicated good quality regarding teacher-ch ild interaction, 1 being the lowest and 4 being the highest. The mean score of the positive relationship subscale $(M=2.60, S D=0.56)$ indicated that some positive relationships existed between teacher and children in the 41 classrooms that were observed. One item (when children misbehave, exp lains the reason for the rule they are breaking) on this subscale with a very low score $(M=1.71, S D=.60)$ suggested that teachers rarely explained the rules children were breaking. One item (talks to the children on a level they can understand) with a high mean score $(\mathrm{M}=3.02, S D=.69)$ indicated that teachers spoke to the children at a level that the children understood. Scores on the other items in this subscale were close to the mean score.

Low scores on the punitiveness subscale indicate good quality in terms of teacher-child interaction. The mean score for this subscale was $1.98(S D=0.58)$, indicating that, in 
general, teachers in the 41 classrooms were not harsh, hostile, and overly controlling in their interactions with the child ren. One item (places high value on obedience) had a high mean score of $3.66(S D=.53)$ suggesting that, generally, preschool teachers in the observed class rooms expected the children to obey them most of the time. One other item (seems to prohibit many of the things the children want to do) had a mean score of $2.71(S D=.93)$, indicating that the preschool teachers of the 41 class rooms frequently prohib it many of the things that the children want to do. The other six items had mean scores in the range of the subscale mean score.

The permis siveness subscale had a mean score of 2.10 (SD $=0.53)$, suggesting that the preschool teachers who participated in the observations frequently avoided disciplining the children even when firmness was necessary to discipline the children. Lower scores on this subscale indicate better quality regarding teacher-child interaction. One item (expects the children to exe rcise self-control) had a very low mean score of $1.56(S D=.71)$. The other three items of the subscale had mean scores in close range to the mean score of the subscale.

Lower scores on the detachment subscale also indicate better quality in regard to teacher-child interaction. This subscale mean score of $1.71(S D=0.49)$ suggested that teachers who took part in the observation did not seem to be distant from the children. Generally, teachers spent much time with children. One item (doesn't seem interested in the children's activities) had a mean score of $2.32(S D=.82)$, indicating that teachers demonstrated some disinterest in children activities. The other four items of the subscale had scores in proximity to that of the subscale mean score.

\subsection{Inferential Statistical Analysis of ECERS-B}

After the development of the ECERS-B, a Pearson correlation test was conducted (a) to determine the significant correlations between subscales and the total score, (b) to determine the significant correlations between the ECERS-B subscales and the total score with the CIS subscales, and (c) to determine the significant correlations of the ECERS-B and CIS subscales with six variables, rural or urban area, center status, number of children, ethnic identification, teacher experience, and teacher education level. A Pearson correlation test was also conducted with the CIS to determine evidence of statistically significant correlations between the subscales. Finally, after the results of these tests indicated that teacher education level correlated significantly with the ECERS-B and CIS subscales, an analysis of variance (ANOVA) test was conducted to determine how much of the variance can be accounted for by teacher education.

The ECERS-B was developed from the ECERS-R and ECERS-E after modifying items in the subscales to create five robust subscales with acceptable reliability estimates for scores on each subscale (space, $\alpha=.56$; activities, $\alpha=.76$; interaction, $\alpha=.79$; math and science, $\alpha=.71$; and language and literacy, $\alpha=.69$ ) and the total instrument, $\alpha=.75$. The
Pears on correlation test indicated that most of the subscales correlated significantly with $p \leq .01$. Interaction with math and science subscale had a weak but statistically significant relationship, $r=.298, p \leq .1$. The space subscale with the interaction subscale and language and the literacy subscale had no statistically significant corre lations.

The total ECERS-B significantly correlated with the five subscales with $p \leq .01$. The total ECERS-B with the activities subscale had a very strong, positive correlation, $r=.896, p$ $\leq .01$. The interaction subscale, math and science subscale, and language and literacy subscale had a strong positive relationship with the total ECERS-B. And, the space subscale had a moderate relationship, $r=.560, p \leq .01$ ).

\subsection{ECERS \& CIS Correlated}

The ECERS-B subscales and the total were correlated with the CIS. The results indicated that the CIS positive relationship subscale had statistically significant correlations with the total ECERS-B and four of its subscales (activities, interaction, math and science, and language and literacy). Two subscales, interaction and language and literacy, had a very strong, positively relationship, $r=.840, p \leq .01$ and $r$ $=.833, p \leq .01$, respectively. The activities subscale and the math and science subscale had moderate correlation, and the total ECERS-B had a high correlation. The space subscale had no statistically significant correlation with the CIS positive relationship.

The CIS detachment subscale had moderate, negative correlations with the ECERS-B subscales except for the space subscale. The total ECERS-B also had a negative, moderate correlation with the CIS detachment subscale, $r=$ $-.594, p \leq .01$. The negative correlations were expected for this subscale because lower scores indicated better teacher-child interaction.

The CIS punitiveness subscale had expected negative correlations with the ECERS-B subscales - except for math and science, but these were not statistically significant. The space and activities subscales were negatively corre lated but were not statistically significant. The interaction subscale and the language and literacy subscale had moderate correlations, $r=-.562, p \leq .01$ and $r=-.434, p \leq .01$, respectively. The total ECERS-B had a weak correlation but statis tically significant, $r=-.293, p \leq .1$.

The CIS permissiveness subscale was correlated to a statistically significant level with the interaction subscale of the ECERS-B, $r=.311, p \leq .05$. This had an unexpected weak, positive relationship. Although the space subscale and the math and science subscale were negatively correlated with the permis siveness subscale, these were not statistically significant. The total ECERS-B was not significantly correlated with the permissiveness subscale.

\subsection{ECERS \& CIS Variables Correlation}

The ECERS-B and CIS subscales were correlated with six independent variables, rural or urban area, center status, number of children, ethnic identification, teacher experience, 
and teacher education level. Of the six variables, teacher education level was the only variable that had statistically significant correlations with different subscales of the ECERS-B and the CIS. This is worth reporting because the mean scores of teachers with more than a high school diplo ma were better than the mean scores of teachers with a high school diploma or less, suggesting that preschool teachers with higher education provide better quality of instruction and care in the preschoolclassroom. This positive relationship is supported in the literature[7-8].

Two of the five ECERS-B subscales had weak but statistically significant correlations with teacher education level. These were interaction $(r=.294, p \leq .1)$ and language and literacy $(r=.264, p \leq .1)$. The total ECERS-B also had a weak but statistically significant correlation with teacher education level $(r=.269, p \leq .1)$.

The CIS positive relationship subscale had a weak but statistically significant correlation with teacher education $(r$ $=.328, p \leq .05$ ). Teachers with more than a high school diplo ma had a higher mean score than teachers with less than a high school diploma, suggesting that teachers with higher level of education have more positive interactions with young children[9]. The CIS detachment subscale had an expected negative correlation that was statistically significant $(r=-.437, p \leq .01)$. The mean score of teachers with more than a high school diploma was lower than for teachers with only a high school diplo ma or less. This was expected because lower scores on punitiveness,permissiven ess, and detachment indicated better teacher-child interaction. Although teachers with more than a high school diploma had a lower mean score on the punitiveness subscale, it was not statistically significant. Teachers with more than a high school diploma had a higher mean score on the permissiveness subscale but this was not statistically significant.

\subsection{CIS \& Pearson Correlation}

A Pearson correlation test was conducted with the CIS subscales. Positive relationship had a moderate, negative correlation with punitiveness and a strong, negative correlation with detachment that were both statistically significant. Punitiveness had a strong, negative correlation with permissiveness that was also statistically significant. No other statistically significant correlations were present.

\subsection{ECERS \& CIS ANOVA Test}

After teacher education was established to be a variable that had statistically significant correlations with the ECERS-B subscales, the total ECERS-B, and the CIS subscales, an ANOVA test was conducted to test mean differences using teacher education level as the independent variable. Eta squared was calculated to determine how much variance can be accounted for by teacher education. The one-way ANOVA test was completed using alpha $=.10$.

The correlations between two ECERS-B subscales, interaction and language and literacy, and the total ECERS-B were statistically significant. Teacher education accounted for $9 \%$ of the variance in regard to interaction $(F=$ $3.700, d f=1 / 39, p \leq .1), 7 \%$ in regard to language and literacy $(F=2.927, d f=1 / 39, p \leq .1)$, and $7 \%$ in regard to the total ECERS-B $(F=3.031, d f=1 / 39, p \leq .1)$.

Regarding the CIS subscales, teacher education accounted for $11 \%$ of the variance in the positive relationship subscale $(F=4.715, d f=1 / 39, p \leq .05)$ and $19 \%$ of the variance in the detachment subscale $(F=9.207, d f=1 / 39, p \leq .01)$. The effect for punitiveness was not statistically significant but $7 \%$ of the variance was accounted for by teacher education.

In summary, the ECERS-B is a scale that was developed from the ECERS-R and the ECERS-E. It is a useful instrument that yields acceptably reliable scores using Be lizean data. Pearson correlation tests indicated statistically significant corre lations a mong the subscales, the total score, and the CIS subscales. After testing the instrument with six independent variables, the scores indicated that teacher education level was a variable that correlated significantly with the ECERS-B subscales, the total, and the CIS subscales. Teacher education was also accountable for a reasonable amount of the variance. The ECERS-B may be used with confidence in the Belizean culture.

\section{Major Conclusions}

From this study, several conclusions can be drawn from the data and analysis. These conclusions address a move toward the improvement of process quality and structural quality in an effort to develop the early childhood education programs in Belize.

The quality of preschool education offered in the rural and urban area and the status of preschools (whether public, private, community, or government-aided) did not differ. Different kinds of schools in rural and urban areas had similar scores on the ECERS-R, ECERS-E, and CIS. This can be explained by the fact that a standardized curriculu m, a standardized schedule, and a standardized list of items for display are recommended by the National Preschool Unit. The district coordinators oversaw all preschools to provide support to preschools in their respective district. This is a positive step toward improving quality.

The major stakeholders commented about child-centered instruction to provide quality preschool education to young children. The national curriculum promoted child-centered activities. This mode of instruction encourages children's self-development and self-expression. Child-centered activities are a suitable means of leaning to use in preschool classrooms with young children in Belize.

The preschool classroom environment should be stimulating to young children. It should be equipped with child-sized furniture, health and safety measures, sensory materials, activity centers, and colorful displays to capture children's attention and hold their interest. Efforts should be made to furnish the preschool classrooms with sufficient materials to accommodate all children and allow them to engage in visual, auditory, and kinesthetic explorations. 
The CIS provided a good measure of teacher-child interactions in Belizean preschools. It had high acceptable reliability scores for each subscale and significantly correlated with teacher education. The CIS positive relationship indicated that some positive teacher-child interactions occur in the classrooms. Although teachers lack qualifications in early childhood education, teachers with many years of teaching experience and training in early childhood workshops accounted for the positive scores on the positive relationship subscale. The CIS is an appropriate measure to collect data on teacher-child interactions in preschool classrooms in Belize.

The recent appointment of district coordinators to assist preschool teachers in their respective districts and the attachment of preschool to the public schools are two initiatives to improve the quality of preschool education in Belize and to provide access. The major stakeholders spoke positively of the district coordinators and the attachment program. These programs are important steps toward improving quality and access of preschool education in Be lize and should be continued.

The lack of early childhood education may affect the quality of preschool programs provided by teachers. According to research, teachers with higher qualifications provide higher quality of early childhood care and interaction[10-16].

The ECERS-R and the ECERS-E did not provide a good measure of the quality of preschool environments in Belize because of the cultural setting and standardized practices performed by teachers. But after modifying these two instruments and developing the ECERS-B with five robust subscales, the ECERS-B measures well because it was uniquely created to accommodated the Belizean culture. The ECERS-B subscale and total had acceptable re liab ility scores. The total mean score of the ECERS-B suggests minimal quality of the preschool environments in Belize. This minimal quality can be accounted for by two factors: the need to improve teacher qualifications in early childhood education and the lack of resources in the classrooms. The scale may be considered and used as an alternative measure for preschool quality in Belize.

\section{Recommendations for Policy and Practice}

During the interviews of the major stakeholders, they indicated little knowledge of the draft early childhood education policy for Belize. I recommend that a committee be formulated to complete the draft policy, publish the document, distribute the document to each preschool center, and provide easy access to the document. The document should contain guidelines for preschool teachers, guidelines for a healthy and safe preschool environment, and the procedures and stipulations for licensing, opening, and operating a preschool program.

Many research studies[10-16] as well as this study indicated that teachers with higher education levels provide better quality of preschool education to young children. I recommend that provisions are made to allow preschool teachers in each district to have the opportunity to acquire at least an associate degree in early childhood education at a reasonable rate. After a reasonable period, a policy should be developed that stipulates the need of an associate degree in early childhood education to certify preschool teachers before they take responsibility of a group of children in any preschool classroom.

The National Preschool Unit currently provides annual workshops for teachers. These workshops are conducted to assist preschool teachers in the development of visual aids, games, puzzles, and materials to use with young children. I recommend that workshops be conducted to address topics such as safety practices, health practices, toileting procedures, routine procedures, informal communications, logical relationships, and the concept of play as a learning strategy. For their attendance, I recommend that teachers acquire credits toward the continuance of their preschool teacher certification.

One major stakeholder mentioned that she works hard to assist teachers who have problems with concept mapping and les son planning. Preschool teachers als o commented that they spend much time developing and writing lesson plans rather than preparing activities for the classroom lessons. There is a national curriculum, but the content is very broad and teachers spend too much time trying to put together concept maps and lesson plans. I recommend that a team of early childhood professionals develop detailed curriculum guides with goals for the month, objectives for the week, suggested activities for each day, and suggested materials. This comprehensive curriculum would allow teachers to spend more time preparing and organizing activities for daily lessons rather than spending the time figuring concept maps and writing less on plans.

Young children need attractive materials that would capture and hold their attention to stimu late their learn ing. I recommend the establishment of a program to develop the physical environment of preschools by locating appropriate physical resources, such as books, materials for fine motor development, and materials for gross motor develop ment.

District coordinators visit preschool classrooms in their respective areas to observe, evaluate, and support teachers. Teachers are provided with a written evaluation of their performance during the observations. Preschool teachers also need to know the quality of their clas sroom environ ment. The use of ECERS-B can provide this information to teachers. I recommend that the district coordinator or an observation team use the ECERS-B to measure the environmental quality of preschool classrooms. The scores of each item, each subscale, and the totalcould be reported to each preschool teacher so that they can use these as indicators of the quality of their preschool environment. The scores would suggest specific areas of strengths and weaknesses. Teachers could then use the scores to address specific areas for the improvement of their classroom environment. I recommend that these observations occur annually so that pres chool teachers, dis trict coord inators, and the National Preschool Unit can track the improvements of each preschool environment. 
Preschool teachers are observed in their classrooms on a regular basis and evaluated on their performance annually by district coordinators. Workshops are conducted nationally and at the district level to address concerns observed during the visits. Preschool teachers are provided with strategies on how to improve the presentations of lessons, but telling preschool teachers what to do to improve and demonstrating are two different concepts. I recommend that a coaching program be developed to assist preschool teachers in the classroom. Coaches can demonstrate effective early literacy strategies, early math and science strategies, and strategies for early physical development with preschool children in the classroom. Preschool teachers would be observers and then discuss the lesson presentation with the coach. The coaches would provide interactive support rather than directive.

Attaching a preschool program to the public schoolsespecially in the rural villages - provided access to young children of low-income backgrounds. Few preschools were attached to public schools in the urban areas. Many children of low-income families live in the urban areas. I recommend that more preschool programs be attached to the primary schools in the urban area. In the long term, this will help to alleviate the poverty situation in towns and major cities in Belize.

\section{Recommendations for Future Research}

Many opportunities for future research in the field of early childhood education are available in Belize. The ECERS-B was developed after mod ifying the ECERS-R and ECERS-E. The ECERS-B was tested to be reliable for the data collected during this study. I recommend that the ECERS-B be tested in future research to measure the quality of the environment with a larger sample in Belize and to test its reliability with this larger sample. The ECERS-B should also be tested in other developing countries with similar early childhood conditions.

Several research studies indicated that children who attend a preschool program perform better than those who do not. It would be interesting go beyond this notion and find out the influence of the physical environ ment on children's learning in Belize. Because the ECERS-B was developed with cultural considerations to measure the preschool environme nts in Belize, I recommend that the instrument be considered as a quality measure and studies be conducted to examine the relationship to student achievement.

No standardized measures to test and track the development of young children exist in Belize. I recommend that major stakeholders take the initiative to identify appropriate instruments to trace the development of young children in different areas such as literacy development, number awareness, and critical thinking. When necessary, these instruments should be modified to accommodate the Belizean culture. I would recommend that the data be kept over a period years for longitudinal studies.

This research indicated that teacher education had statistically significant correlations with the ECERS-B and accounted for a low but significant percentage of the variance. Note that the teachers in this study did not have education qualifications in early childhood. Since August 2007 , only one early childhood education associate degree pilot program is offered to teachers by one institution. I recommend that after the first year, an experimental design study be conducted to find out the effectiveness of the program. This can be done by using the ECERS-B or a similar appropriate instrument. This study would find out if teachers in the pilot program in Belize provide higher quality preschool education than the teachers in the control group. A similar study can be done after the graduation of the first cohort to find out the effectiveness of the associate degree program in Belize.

Research studies also suggested that highly qualified teachers with early childhood education qualifications provide higher quality of preschool programs. I recommend that after the graduation of the first cohort in the early childhood education pilot program a study be conducted to compare the performance of teachers who had an associate degree in early childhood education and teachers who had a higher degree in another area other then early childhood education.

\section{Conclusions}

In the early 1990s, I saw the importance of early childhood education when I wrote my thesis in Belize and developed a passion in that area. All the preschools were private and few, if any, existed in the villages. The results of the study suggested how important a preschool education is to the cognitive, social, and physical development of young children. I was impressed with the effects of a preschool program on my sample and was also concerned that all young children did not have access to the opportunity. Looking back after 18 years, I must say that I am very proud of how far my country has progressed regarding preschool education programs.

I am delighted that I took the opportunity to conduct this study that described the current status of preschool education in Be lize. When I first exp lored the idea of this national study, I was a little uneasy about what I would find. I did not want to submit a report with all negative statements to describe the status of preschool education to my colleagues in Belize. As I conducted my observations, I was impressed by the efforts that were being made to provide access to young children and to improve the quality of preschooleducation in Belize. I was ecstatic.

The first program that impressed me was the attachment program that the government recently initiated. Attaching preschools to the public primary schools was a great way to provide access to young children especially those in the lower-income areas, the villages. The second program that astonished me was the preschool district coordinator program that commenced in September 2007. The major stakeholders did not simply decide to establish more preschool programs without support. Rather, they provided coordinators in each district to mon itor and to assist teachers to develop the quality of their programs.

Getting deeper in the study with the observations and the 
interviews, I was amazed by the role and involvement of the National Preschool Unit to develop the quality of early childhood programs. The development of a standardized curriculum, standardized classroom routine schedule, and a standardized list of basic display chart and materials for each preschool classroom was impressive. This standardization was applied to all preschool classrooms around the country, rural, urban, public, and private, along with annual workshops. This was impressive and brought to my attention that this may have been the reason why the scores of the observation instruments did not differ in regard to area and type of preschool.

Then to top it off was the development of an associate degree pilot program in early childhood education that commenced in fall 2007. Although the program caters to a small group of early childhood education teachers concentrated in one district, it is a great step toward getting preschool teachers qualified. Increasing the number of teachers in the program and providing the program to the other five districts would be the next step to increase the rate of qualifying preschool teachers.

Although the quality of the preschool environments was scored in the minimal range due to the lack of financial resources and physical resources, these four positive initiatives will improved the quality of preschool education in Belize. With a conscious effort to promote and provide safe, healthy, and attractive learning environments for young children, the preschool education will continue to develop to the point that it can be compared with the standards and quality of preschool programs in other countries around the world. The process used might be applicable to developing countries in similar circumstances.

One major stakeholder emphasized, "I have seen a lot of improvements. And when I say a lot of improvements, I mean a lot of improvements because the teachers, the teachers are exc ited and I am excited ...." I must say that I too am extremely excited about the direction of the progress and development of preschool education in Belize, and I can see why preschool stakeholders were excited about the program. The country has recognized the importance of preschool education and has embarked on initiatives to develop the program. It would be my honor to participate in this endeavor. This attention to early childhood education has the possibility to take Belize's economy and social structure to the next level. This is certainly something to be excited about and to celebrate.

\section{ACKNOWLEDGEMENTS}

To my committee members: Dr. Kasten, my dissertation chairperson, you have been a great mentor. Dr. Salmón and Dr. Wood, for your genuine support at UNF and FIE. Dr. Williams, you have inspired me with your consideration and gentle words of support.

To my FIE family, especially Dr. Fountain, Dr. Cosgrove, Dr. Wehry, Dr. Goudy, Bronwyn, Howaida, Kelly, Angi,
Cathye, Cindy, Dave, Kristi, and everyone else I did not mention.

To Mom, Dad, Celi (my sister), Landy, and Aldo (my brothers): I love you all so very much and would not have gotten through this without your patience and support.

To Valerie Vernon, my Besheret, I thank you from the bottom of my heart for your continuous love, support, and encouragement.

To all my extended family and friends in Belize, especially those on the is land of Caye Caulker: Gracias. And to all those who assisted me in making my research possible, especially the preschool teachers, directors/principals, coordinators, stakeholders in early childhood education, and the Ministry of Education: Thank you.

\section{REFERENCES}

[1] Linda M. Espinosa, "High-quality Preschool: Why We Need It and What It Looks Like", Preschool Policy Matters, vol.1, pp.1-12, 2002.

[2] Nicholas Zill, Gary Resnick, Kwang Kim, Kevin O'Donnell, Alberto Sorongon, Ruth Hubbell McKey, Shefali Pai-Samant, Cheryl Clark, Robert O'Brien, Mary Ann D'Elio, Head Start FACES 2000: A Whole-child Perspective on Program Performance, Department of Health and Human Services Washington, DC: USA, 2003.

[3] Gitanjali Saluja, Diane M. Early, Richard M. Clifford, "Demographic Characteristics of Early Childhood Teachers and Structural Elements of Early Childhood and Education in the United States", Early Childhood Research \& Practice, vol.4, no.1, pp.1-20, 2002.

[4] Thelma Harms, Richard M. Clifford, Debby Cryer, Early Childhood Environment Rating Scale-Revised, Teachers College Press, New York: USA, 2005.

[5] Kathy Sylva, Iram Siraj-Blatchford, Brenda Taggart, Assessing Quality in the Early Years: Early Childhood Environment Rating Scale-Extension, Trentham Books Limited, Staffordshire: England, 2006.

[6] Jeffery Arnett, "Caregivers in Day-care Centers: Does Training Matter?" Journal of Applied Development Psychology, vol.10, pp.541-552, 1989.

[7] Richard Ruopp, Jeff Travers, Frederic Glantz, Craig Coelen, Children at the Center: Summary Findings and Their Implications: Final Report of the National Day Care Study, Abt Associates, MA: USA, 1979.

[8] Marcy Whitebook, Carollee Howes, Deborah Phillips, Who Cares? Child Care Teachers and the Quality of Care in America: The Final Report of the National Child Care Staffing Study. Child Care Employee Project, Oakland, CA:USA, 1989.

[9] Laura E Berk, "Relationship of Caregiver Education to Child-oriented Attitudes, Job Satisfaction, and Behaviors Toward Children", Child Care Quarterly, vol.14, pp.103-129, 1985.

[10] W. Steven Barnett, "Better Teachers, Better Preschools: 
Student Achievement Linked to Teacher Qualification", Preschool Policy Matters, vol.2,pp.1-12, 2003.

[11] William L. Sanders, Sandra P. Horn, "Research Findings from the Tennessee Value-added Assessment System (TVAAS) Database: Implications for Educational Evaluation and Research", Journal of Personal Evaluation in Education, vol.12, no.3, pp.247-256, 1998.

[12] William Sanders, June C. Rivers, Research Progress Report: Cumulative and Residual Effects of Teachers on Future Student Academic Achievement. Value-Added Research and Assessment Center, Knoxville: USA, 1996.

[13] William Sanders, Keith J. Topping, "Teacher Effectiveness and Computer Assessment of Reading: Relating Value Added and Learning Information System Data", School
Effectiveness and School Improvement, vol.11, no.3, pp.305-337, 2000.

[14] Jaap Scheerens, Roel J. Bosker, The Foundations of Educational Effectiveness, Pergamon, New York: USA, 1997.

[15] Marcy Whitebook, Bachelor's Degrees Are Best: Higher Qualifications for Prekindergarten Teachers Lead to Better Learning Environments for Children. Trust for Early Childhood, Washington, DC: USA, 2003.

[16] S. Paul Wright, Sandra P. Horn, William L. Sanders, "Teachers and Classroom Context Effects on Student Achievement: Implications for Teacher Evaluation", Journal of Personnel Evaluation in Education, vol.11, no.1, pp.57-67, 1997. 